\title{
A influência do método de musicoterapia de John Bean e da musicoterapia EM GERAL NA REPRESENTAÇÃo ESPACIAL DO CORPO DE PESSOAS COM PARALISIA CEREBRAL (2004 -2010)
}

THE INFLUENCE OF JOHN BEAN'S MUSIC THERAPY METHOD AND OF MUSIC THERAPY IN GENERAL IN BODY SPATIAL REPRESENTATION IN PEOPLE WITH CEREBRAL PALSY (2004-2010)

\author{
Jose M. ${ }^{a}$ Fernández BATANERO ${ }^{1}$ \\ Micaela Cardoso ROGÃO²
}

RESUMO: acreditar no princípio da normalização, pressupõem acreditar que todas as pessoas merecem uma sociedade que atenda aos direitos humanos. Uma sociedade que vá ao encontro das características e das particularidades de cada pessoa, atendendo de modo diferenciado às necessidades dos seus elementos, sejam eles ditos "normais", ou com problemáticas. Assim, este artigo, tendo por base um método de investigação quantitativo/qualitativo, aborda a influência do método de musicoterapia de John Bean e da musicoterapia em geral na representação espacial do corpo de pessoas com paralisia cerebral.

PALAVRAS-CHAVE: Educação Especial; Musicoterapia; Método de musicoterapia de John Bean; Representação espacial do corpo; Paralisia cerebral.

ABSTRACT: Believing in the principle of normalization implies believing that all people deserve a society that defends human rights. A society that respects each person's characteristics and particularities, must respond differently to the needs of its constituents, whether or not they are "normal" or have problems. Thus, this article, based on a quantitative/qualitative research approach, discusses the influence of John Bean's music therapy method and of music therapy in general on the spatial representation of the body in people with cerebral palsy.

KEYWORDS: Music therapy; John Bean Method; Spatial Representation of the Body; Cerebral Palsy.

\section{INTRODUÇÃo}

O recurso à musicoterapia remonta à antiguidade. Toro (2000) refere que já na Antiguidade Grega, em vários escritos, se fazem referências ao poder terapêutico - religioso do cântico.

São várias as definições sobre o conceito de musicoterapia. Prieto refere que:

[...] La musicoterapia parte de la utilización de sonidos y músicas diversos como herramientas de intervenciones reeducatvas y terapéuticas. La música incide en el ser humano tanto en sus procesos fisiológicos como psicológicos, ya que no es posible encontrar la línea divisoria entre ambos, que están estrechamente interrelacionados. (PRIETO, 1999 ,p.141).

A escolha concreta do método de musicoterapia de John Bean, neste artigo, deve-se ao fato de ser um método com atividades bem definidas, fazendo dele,

\footnotetext{
${ }^{1}$ Universidade de Sevilha, Espanha - Ciências da Educação - batanero@us.es

${ }^{2}$ Universidade de Sevilha, Espanha- Ciências da Educação - micaelacr@hotmail.com
} 
segundo o próprio autor (1999, citado em Wigram, et al, 1999), um tipo de intervenção diretiva que permite ter segurança e clareza nos propósitos e atingir objetivos mais específicos.

É também pertinente clarificar o conceito de esquema corporal, que segundo Aljuriaguerra e Stucki (1972, apud RODRIGUES, 1998, p.20), se define como:

[...] uma estrutura neuromotora que permite ao indivíduo estar consciente do seu corpo anatómico, ajustando-o rapidamente às solicitações de situações novas e desenvolvendo acções de forma adequada, num quadro de referência espaçotemporal dominado pela orientação direita-esquerda.

No que se refere à paralisia cerebral, González (2003) refere que esta questão se define como um transtorno motor persistente, originado por uma lesão no cérebro ainda imaturo. Esta lesão ocorre no período pré-natal, neonatal ou pós-natal.

Herceberg (2005, Maio-Junho) salienta que a lesão cerebral pode suceder durante a gestação, durante o parto ou durante os primeiros anos de vida. Esta mesma lesão pode dever-se a diferentes causas, nomeadamente uma infecção intrauterina, malformações cerebrais, nascimento prematuro, assistência incorreta durante o parto .

Tendo em conta a musicoterapia em geral e conhecendo o método de musicoterapia de John Bean, o qual, como já foi referido, se apresenta como um método diretivo e com propostas bem definidas, as quais são destinadas ao movimento; ao controle da cabeça e ao controle dos membros superiores e inferiores, formula-se a seguinte questão: “ Qual a influência do método de musicoterapia de John Bean e da musicoterapia em geral na representação espacial do corpo de pessoas com paralisia cerebral?"

Assim, é objetivo geral, deste artigo, abordar a influência do método de musicoterapia de John Bean e da musicoterapia em geral na representação espacial do corpo de pessoas com paralisia cerebral. Dentro deste objetivo geral, podem-se enunciar objetivos específicos relacionados com a representação espacial do corpo, sendo eles: Investigar a influência do método de musicoterapia de John Bean e da musicoterapia em geral na capacidade de reconhecimento do corpo; construção do corpo; representação do corpo; reconhecimento, construção e representação homolateral do corpo e reconhecimento, construção e representação heterolateral do corpo.

\section{Metodologia}

\subsection{Metodologia Quantitativa}

\subsubsection{Amostra}

Tendo a Associação de Paralisia Cerebral de Coimbra deferido o estudo alvo deste artigo que teve lugar na Quinta da Conraria, procedeu-se à definição da 
população. A mesma foi composta por todos os alunos que frequentavam a Quinta da Conraria, e quando me refiro a todos os alunos, refiro-me quer a alunos do sexo masculino, quer a alunas do sexo feminino, com paralisia cerebral e sem deficiência mental associada.

Apesar do último critério (sem deficiência mental) ter reduzido substancialmente o número da população, tal fato justifica-se pela necessidade de clareza do estudo.

Caso contrário, até que ponto poderíamos saber se os resultados obtidos no instrumento de recolha de dados se encontravam comprometidos devido a existência de um quociente intelectual considerado inferior.

Através de amostragem aleatória, foi assim sorteado, dentro da população, um grupo experimental e um grupo de controle. Inicialmente, os grupos possuíam quatro elementos cada, mas com o decorrer do tempo, o grupo experimental perdeu dois elementos, restando-lhe apenas os outros dois. amostra.

Vejamos, de acordo com os gráficos que se seguem, a caracterização da

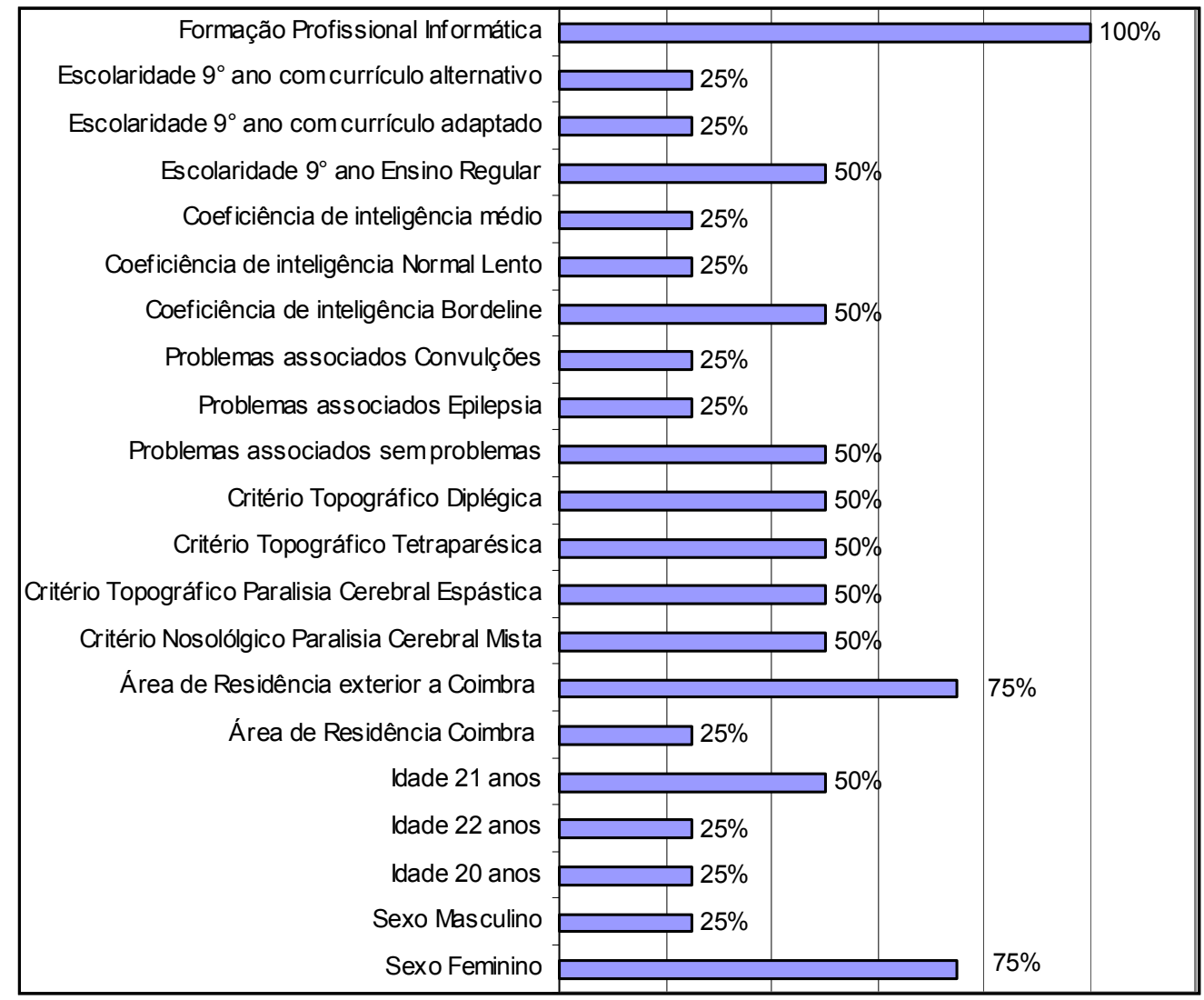

Gráfico 1 - Caracterização do Grupo de Controle 


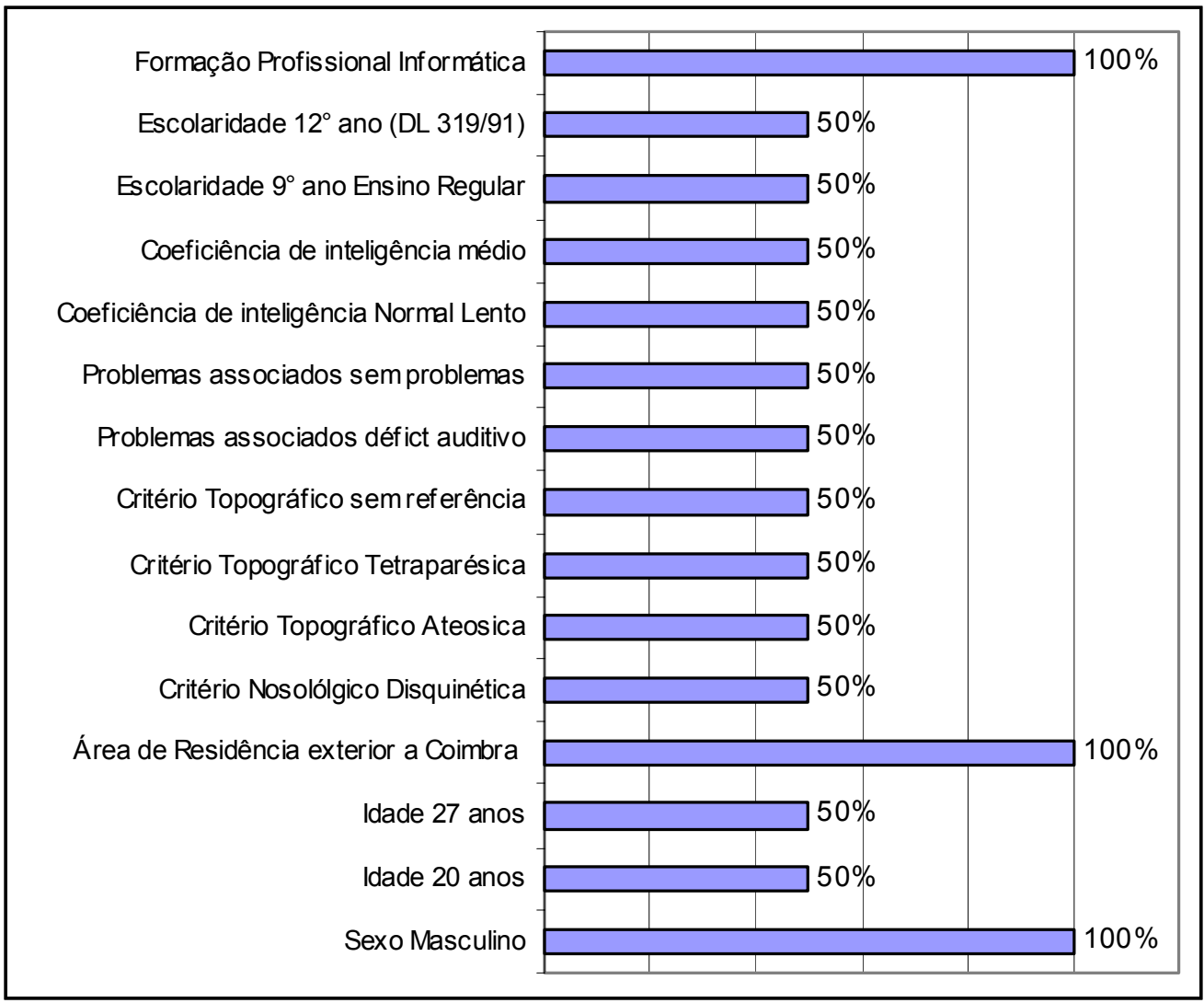

Gráfico 2 - Caracterização Grupo Experimental.

Constituídos os dois grupos, o grupo de controle e o grupo experimental, os mesmos foram inicialmente submetidos a uma fase de teste, mais propriamente ao teste experimental de representação espacial do corpo.

Em seguida, numa fase de intervenção, o grupo experimental foi alvo do método de musicoterapia de John Bean, durante um período aproximado de cinco meses, uma vez por semana, tendo cada sessão a duração também aproximada de 45 minutos.

Após a intervenção, os dois grupos foram submetidos a outra fase de teste, ou seja realizaram novamente o teste experimental de representação espacial do corpo.

\subsubsection{Instrumento de Recolha de Dados}

A utilização do teste experimental de representação espacial do corpo, do professor doutor David Rodrigues, deve- se ao fato do seu autor tê-lo elaborado para a população em questão e assim, tê-lo: 
[...] concebido de forma a poder ser respondido através de modalidades várias: motoras e verbais. No caso limite de uma criança com uma importante disfunção motora que a impedisse, por exemplo, de apontar o objecto ou local pretendido... o teste poderia ser respondido unicamente através da dirrecionalidade do olhar. (RODRIGUES, 1998, p.97).

Este teste experimental de representação espacial do corpo é composto por três partes distintas: Reconhecimento, Construção e Representação. Dentro da primeira e da segunda parte existem itens que são duplos e triplos, e que devem ser respondidos inicialmente de forma homolateral (prova homolateral), e depois de forma heterolateral (prova heterolateral). No que se refere à terceira parte, existem seis itens que devem ser respondidos na prova homolateral e quatro itens que devem ser respondidos na prova heterolateral.

\subsection{Metodologia Qualitativa}

\subsubsection{AMOSTRA}

Nesta parte da metodologia, a amostragem foi não probabilística por conveniência. Pois de todos os professores e instituições contatadas, foram realizadas entrevistas aos professores e alunos que mostraram interesse nesse sentido.

O grupo de alunos entrevistados é composto por três elementos. Dois destes entrevistados fazem parte do grupo experimental submetido às sessões de musicoterapia de John Bean e ao teste experimental de representação espacial do corpo do Professor Doutor David Rodrigues, na já referida Associação de Paralisia Cerebral de Coimbra, mais em concreto, na Quinta da Conraria.

Esta amostra caracteriza-se por todos os seus elementos serem portadores de paralisia cerebral e serem do sexo masculino. A sua média de idade é de 23,3 anos. A área de residência é exterior a Coimbra e os seus elementos encontram-se, em média, na instituição há 14,2 anos. Como perspectivas para o futuro, surgem ambições como vir a trabalhar na área da informática, arranjar emprego, ou simplesmente colocar betume nos carros.

São inúmeras as atividades desenvolvidas pelos alunos na instituição. Destaca-se em primeiro lugar a fisioterapia. Em seguida e em situação de empate: a terapia ocupacional e o curso de informática e depois também em situação de empate: a psicologia, o curso de bate chapas, o curso de estofador, a hipoterapia, a terapia da fala e a ocupação de tempos livres.

Os três entrevistados, além das sessões de musicoterapia de John Bean, das quais afirmam terem gostado, não frequentaram, anteriormente, qualquer experiência do gênero.

No que se refere aos professores entrevistados, a maioria é do sexo masculino, pois os professores representam $71 \%$. Enquanto que as professoras entrevistadas representam, apenas $29 \%$. 
Cem por cento dos entrevistados exercem a sua profissão em instituições direcionadas para o ensino especial.

É notória a variedade de problemáticas com que os professores de musicoterapia trabalham. Dentro desta variedade, destaca-se a paralisia cerebral que representa $30 \%$, enquanto que as outras problemáticas representam, isoladamente, apenas $7 \%$.

Dois dos professores entrevistados declararam trabalhar com alunos com paralisia cerebral cujas idades vão dos doze aos dezesseis anos.

Dos vários motivos que trouxeram os professores para o mundo da musicoterapia, destaca-se o fator "convite" com $44 \%$.

Verifica-se que os professores trabalham, na área da musicoterapia, entre os três e os dezesseis anos de serviço.

O critério que é tido em maior conta na formação dos grupos, de alunos, de musicoterapia, é o critério da faixa etária. A duração das sessões de musicoterapia varia, no entanto, destacam-se as sessões de 45 minutos que representam $30 \%$ das opções. A frequência das mesmas varia, contudo a regularidade de duas vezes por semana apresenta maior percentagem.

Das inúmeras atividades contempladas pelos professores, na reabilitação de pessoas com paralisia cerebral, a atividade que apresenta maior incidência é o relaxamento.

\subsubsection{Instrumentos de Recolha de Dados}

A elaboração da entrevista aos alunos que beneficiaram de sessões de musicoterapia e da entrevista aos professores de musicoterapia teve como base os objetivos já referidos neste artigo. A partir deles, foram construídas as categorias e a partir destas foram formulados os guiões das entrevistas ${ }^{3}$, ou seja, as perguntas. Validadas as ditas entrevistas foram as mesmas, finalmente, aplicadas.

\section{Análise de Dados}

\subsection{Análise de Dados Quantitativos}

A tabela que se segue permite analisar os resultados, expressos em pontos, obtidos no teste experimental de representação espacial do corpo.

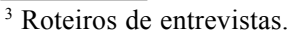


Tabela 1 - Resultados Obtidos no Teste Experimental de Representação Espacial do Corpo (totais expressos em pontos).

\begin{tabular}{|c|c|c|c|c|}
\hline $\begin{array}{l}\text { Partes e Provas do } \\
\text { Teste /Grupos }\end{array}$ & $\begin{array}{c}\text { Grupo de } \\
\text { Controle } \\
(\mathrm{N}=4) \\
\text { Antes da } \\
\text { intervenção } \\
\end{array}$ & $\begin{array}{c}\text { Grupo de } \\
\text { Controle } \\
(\mathrm{N}=4) \\
\text { Depois da } \\
\text { intervenção }\end{array}$ & $\begin{array}{c}\text { Grupo } \\
\text { Experimental } \\
(\mathrm{N}=2) \\
\text { Antes da } \\
\text { intervenção } \\
\end{array}$ & $\begin{array}{c}\text { Grupo } \\
\text { Experimental } \\
(\mathrm{N}=2) \\
\text { Depois da } \\
\text { intervenção }\end{array}$ \\
\hline Reconhecimento & 50 & 55 & 29.5 & 29 \\
\hline Construção & 76 & 89.5 & 45 & 46.5 \\
\hline Representação & 100.5 & 122 & 57.5 & 91.5 \\
\hline Homolateral & 104.5 & 123.5 & 53.5 & 56.5 \\
\hline Heterolateral & 122 & 143 & 78.5 & 110.5 \\
\hline
\end{tabular}

Observando os resultados obtidos, verifica-se que excetuando os resultados da parte do reconhecimento em que o grupo experimental, após a intervenção, apresentou uma pontuação inferior (meio ponto), em todas as outras provas e partes, a pontuação de ambos os grupos foi sempre superior após a intervenção. Assim vejamos:

- Na parte do reconhecimento, o grupo de controle obteve, antes da intervenção, 50 pontos e após a intervenção, obteve 55 pontos. Cinco pontos a mais após a intervenção.

- Na parte da construção, o mesmo grupo conseguiu, antes da intervenção, 76 pontos e após a intervenção, 89,5 pontos. Treze pontos e meio a mais, após a intervenção.

- Na parte da construção, o grupo experimental obteve, antes da intervenção, 45 pontos e após a intervenção, obteve 46,5 pontos. Um ponto e meio a mais, após a intervenção.

- Na parte da representação, o grupo de controle conseguiu, antes da intervenção, 100,5 pontos e após a intervenção, 122 pontos. Vinte e um pontos e meio a mais, após a intervenção.

- Na mesma parte, o grupo experimental obteve, antes da intervenção, 57,5 e após a intervenção, obteve 91,5 pontos. Trinta e quatro pontos a mais, após a intervenção.

- No que se refere à prova homolateral, o grupo de controle somou, antes da intervenção, 104,5 e depois da mesma, 123,5. Dezenove pontos a mais, após a intervenção.

- Relativamente à mesma prova, o grupo experimental conseguiu, antes da intervenção, 53,5 e depois da mesma, 56,5. Três pontos a mais, após a intervenção.

- No que se refere à prova heterolateral, o grupo de controle obteve, antes da intervenção, 122 e depois da mesma, 143. Vinte e um pontos a mais, após a intervenção. 
- Relativamente à mesma prova, o grupo experimental somou, antes da intervenção, 78,5 e depois da mesma, 110,5. Trinta e dois pontos a mais, após a intervenção.

A tabela que se segue permite analisar a média dos resultados, expressa em pontos, obtida no teste experimental de representação espacial do corpo.

Tabela 2 - Média dos Resultados Obtidos no Teste Experimental de Representação Espacial do Corpo (média expressa em pontos).

\begin{tabular}{ccccc}
\hline Partes e Provas do & $\begin{array}{c}\text { Grupo de } \\
\text { Controle } \\
\text { Teste /Grupos }\end{array}$ & $\begin{array}{c}\text { Grupo de } \\
\text { Controle } \\
(\mathrm{N}=4)\end{array}$ & $\begin{array}{c}\text { Grupo } \\
\text { Experimental } \\
(\mathrm{N}=2)\end{array}$ & $\begin{array}{c}\text { Grupo } \\
\text { Experimental } \\
(\mathrm{N}=2)\end{array}$ \\
& intervenção & $\begin{array}{c}\text { Depois da } \\
\text { intervenção }\end{array}$ & $\begin{array}{c}\text { Antes da } \\
\text { intervenção }\end{array}$ & $\begin{array}{c}\text { Depois da } \\
\text { intervenção }\end{array}$ \\
\hline Reconhecimento & 12,5 & 13,75 & 14,75 & 14,5 \\
Construção & 19 & 22,375 & 22,5 & 23,25 \\
Representação & 25,125 & 30,5 & 28,75 & 45,75 \\
Homolateral & 26,125 & 30,875 & 26,75 & 28,25 \\
Heterolateral & 30,5 & 35,75 & 39,25 & 55,25 \\
\hline
\end{tabular}

Observando a média dos resultados obtidos, verifica-se novamente que excetuando os resultados da parte do reconhecimento em que o grupo experimental, após a intervenção, apresentou uma pontuação inferior em vinte e cinco centésimas, em todas as outras provas e partes a pontuação de ambos os grupos foi sempre superior após a intervenção. Pois consideremos o seguinte:

- Na parte do reconhecimento, o grupo de controle obteve, antes da intervenção, a média de 12,5 e após a intervenção, obteve a média de 13,75. Um vírgula vinte e cinco pontos a mais, após a intervenção.

- Na parte da construção, o mesmo grupo conseguiu, antes da intervenção, a média de 19 pontos e após a intervenção, a média de 22,375. Três vírgula trezentos e setenta e cinco pontos a mais, após a intervenção.

- Na parte da construção, o grupo experimental obteve, antes da intervenção, a média de 22,5 e após a intervenção, obteve a média de 23,25 . Setenta e cinco décimas a mais, após a intervenção.

- Na parte da representação, o grupo de controle conseguiu, antes da intervenção, a média de 25,125 e após a intervenção, a média de 30,5. Cinco vírgula trezentos e setenta e cinco pontos a mais, após a intervenção.

- Na mesma parte, o grupo experimental obteve, antes da intervenção, a média de 28,75 pontos e após a intervenção, obteve a média de 45,75. Dezessete pontos a mais, após a intervenção.

- No que se refere à prova homolateral, o grupo de controle somou, antes da intervenção, a média de 26,125 e depois da mesma, a média foi de 30,875. Quatro vírgula setecentos e cinquenta pontos a mais. 
- Relativamente à mesma prova, o grupo experimental conseguiu, antes da intervenção, 26,75 e depois da mesma, 28,25. Um ponto e meio a mais, após a intervenção.

- No que se refere à prova heterolateral, o grupo de controle obteve, antes da intervenção, 30,5 e depois da mesma, 35,75. Cinco vírgula vinte e cinco pontos a mais, após a intervenção.

- Relativamente à mesma prova, o grupo experimental somou, antes da intervenção, 39,25 pontos e depois da mesma, 55,5 pontos. Seis pontos a mais, após a intervenção.

Veja-se agora a diferença da média dos resultados obtidos no teste experimental de representação espacial do corpo, diferença esta expressa em pontos.

Tabela 3 - Diferença da Média dos Resultados Obtidos no Teste Experimental de Representação Espacial do Corpo (diferença expressa em pontos).

\begin{tabular}{ccc}
\hline $\begin{array}{c}\text { Partes e Provas do } \\
\text { Teste /Grupos }\end{array}$ & $\begin{array}{c}\text { Grupo experimental antes e } \\
\text { depois da intervenção }\end{array}$ & $\begin{array}{c}\text { Grupo de controle e grupo } \\
\text { experimental depois da } \\
\text { intervenção }\end{array}$ \\
\hline Reconhecimento & $-0,25$ & 0,75 \\
Construção & 0,75 & 0,875 \\
Representação & 17 & 15.25 \\
Homolateral & 1,50 & -2.625 \\
Heterolateral & 16 & 19.50 \\
\hline
\end{tabular}

Analisando a diferença da média dos resultados obtidos pelo grupo experimental antes e depois da intervenção (segunda coluna), observamos que excetuando os resultados da parte do reconhecimento, em que o grupo em questão obteve $-0,25$, decorrente do resultado inferior obtido pelo grupo experimental após a intervenção; em todas as outras provas e partes, após a intervenção, o grupo experimental apresentou sempre uma diferença positiva.

Poderíamos dizer que esta diferença foi mais significativa na parte da representação (17), em seguida na prova heterolateral (16), depois na prova homolateral $(1,50)$ e finalmente na parte da construção $(0,75)$.

Analisando a diferença da média dos resultados obtidos entre o grupo de controle e o grupo experimental depois da intervenção (terceira coluna), observamos que excetuando os resultados da prova homolateral em que o grupo experimental obteve, após a intervenção, um resultado inferior ao grupo de controle (-2.625); em todas as outras provas e partes, após a intervenção, o grupo experimental apresentou sempre uma diferença positiva. Diferença esta que foi mais notável na prova heterolateral, em seguida na parte da representação, na parte da construção e finalmente na parte do reconhecimento. 
O gráfico que se segue expressa a média dos resultados obtidos, pelo grupo experimental antes e depois da intervenção, no teste experimental de representação espacial do corpo.

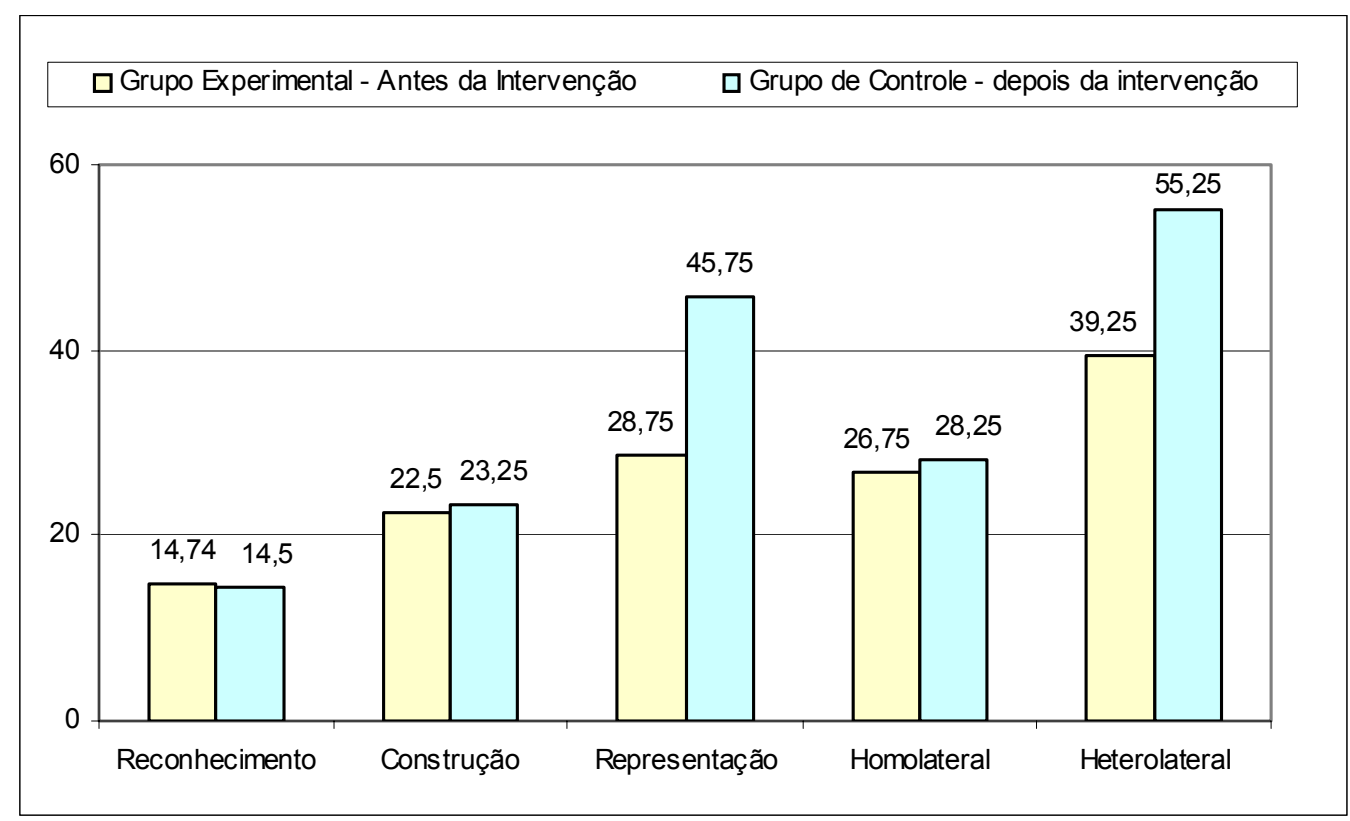

Gráfico 3 - Média dos Resultados Obtidos, pelo Grupo Experimental antes e depois da Intervenção, no Teste Experimental de Representação Espacial do Corpo (média expressa em pontos).

No gráfico, observa-se que excetuando os resultados da parte do reconhecimento, em que o grupo experimental obteve $-0,25$, após a intervenção, apresentou melhores resultados em todas as outras provas e partes.

Pois vejamos:

- Na parte da construção, o grupo experimental obteve, antes da intervenção, a média de 22,5 e após a intervenção, obteve a média de 23,25 . Setenta e cinco décimas a mais, após a intervenção.

- Na parte da representação, o grupo experimental obteve, antes da intervenção, a média de 28,85 pontos e após a intervenção, obteve a média de 45,75 pontos. Dezessete pontos a mais, após a intervenção.

- Relativamente à prova homolateral, o grupo experimental conseguiu, antes da intervenção, 26,75 pontos e depois da mesma, 28,5 vírgula vinte e cinco pontos. Um ponto e meio a mais, após a intervenção.

- No que se refere à prova heterolateral, o grupo experimental somou, antes da 
intervenção, 39,25 pontos e depois da mesma, 55,25 pontos. Seis pontos a mais, após a intervenção.

O próximo gráfico expressa a média dos resultados obtidos, pelo grupo de controle e pelo grupo experimental após a intervenção, no teste experimental de representação espacial do corpo, encontrando-se esta média expressa em pontos.

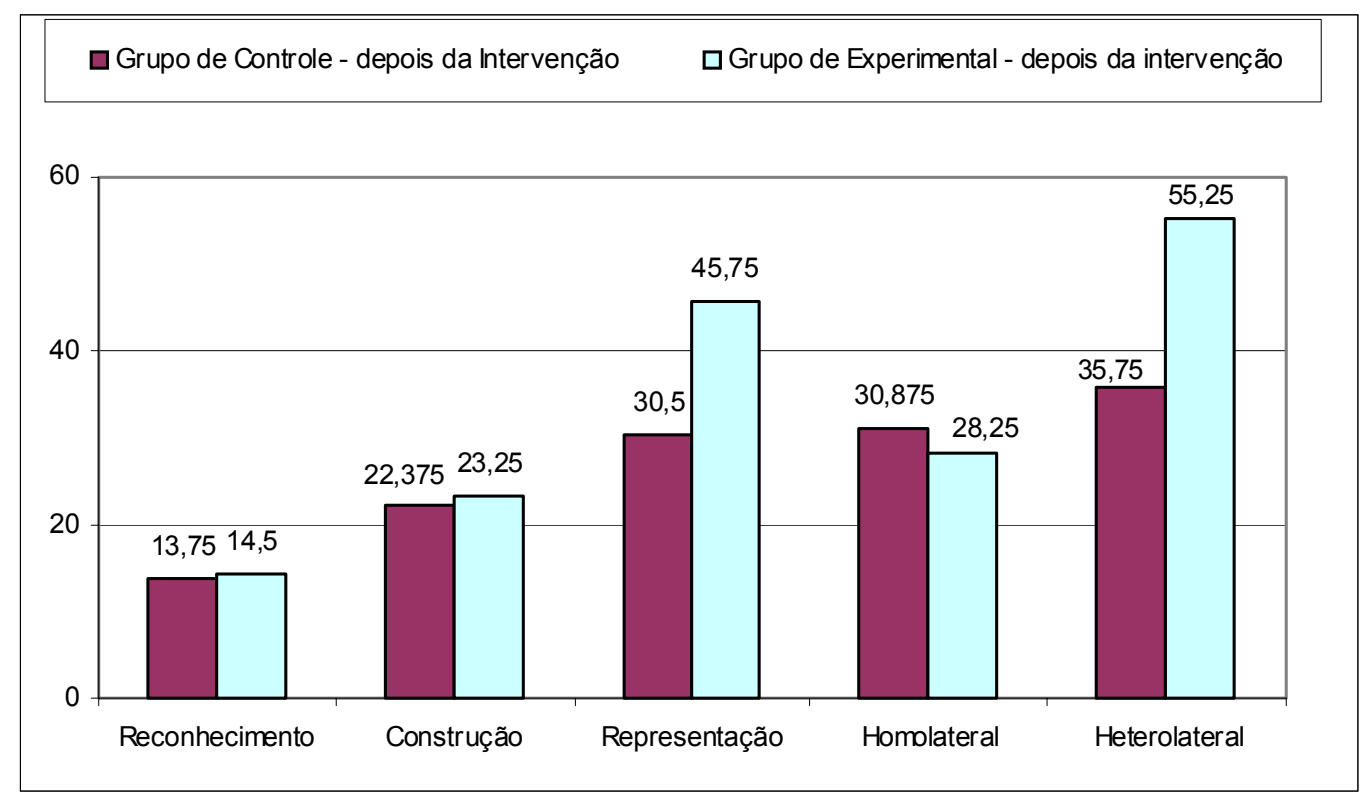

Gráfico 4 - Média, em pontos, dos Resultados Obtidos, pelo Grupo de Controle e pelo Grupo Experimental após a Intervenção, no Teste Experimental de Representação Espacial do Corpo.

Poderemos referir que excetuando a prova homolateral, em que o grupo experimental obteve $-2,625$ pontos; em todas as outras provas e partes, no final da intervenção, o grupo em questão apresentou melhores resultados que o grupo de controle. Pois consideremos:

- Após a intervenção, na parte do reconhecimento, o grupo experimental obteve mais 0,75 de média que o grupo de controle.

- Após a intervenção, na parte da construção, o grupo experimental obteve mais 0,875 de média que o grupo de controle.

- Após a intervenção, na parte da representação, o grupo experimental obteve mais $+15,25$ de média que o grupo de controle.

- Após a intervenção, na prova heterolateral, o grupo experimental obteve mais 19,5 de média que o grupo de controle. 


\subsection{Análise de Dados Qualitativos}

No que se refere ao reconhecimento do corpo, podemos analisar os seguintes dados:

- Cem por cento dos alunos entrevistados afirmam, na questão 10, terem sentido, após as sessões do método de musicoterapia de John Bean, menos dificuldade no reconhecimento do corpo.

- Cerca de oitenta e cinco por cento dos professores entrevistados, pois a restante percentagem não se pronunciou, referiram que e a musicoterapia no geral melhora a capacidade de reconhecimento do corpo de pessoas com paralisia cerebral (questão 12).

- Aproximadamente $57 \%$ dos professores entrevistados, pois a restante percentagem também não se pronunciou, referiram que o método de musicoterapia de John Bean melhora a capacidade de reconhecimento do corpo de pessoas com paralisia cerebral (questão 19).

Sobre a construção do corpo, é possível analisar que:

- Cerca de oitenta e cinco por cento dos professores entrevistados referiram que a musicoterapia em geral melhora a capacidade de construção do corpo de pessoas com paralisia cerebral (questão 13). A restante percentagem não emitiu nenhuma opinião.

- Perto de $57 \%$ dos professores entrevistados, pois a restante percentagem não se pronunciou, referiram que o método de musicoterapia de John Bean melhora a capacidade de construção do corpo de pessoas com paralisia cerebral (questão 20).

- Cem por cento dos alunos entrevistados referem, na questão 11, ter sido mais fácil, após as sessões de musicoterapia, levar a cabo atividades relacionadas com a construção do corpo.

Sobre a representação do corpo, verifica-se que:

- Dos professores entrevistados, cerca de 85\% referem, na questão 14, que a musicoterapia em geral, quando aplicada a pessoas com paralisia cerebral melhora a capacidade de representação do corpo. A percentagem que falta não emitiu considerações sobre o assunto.

- Inquiridos, os professores entrevistados, cerca de 57\%, referem, na questão 21, que o método de musicoterapia de John Bean, quando aplicado a pessoas com paralisia cerebral, melhora a capacidade de representação do corpo. A restante percentagem não se pronunciou.

- Também na representação do corpo, 100\% dos alunos entrevistados referem, na questão 12, ter sido mais fácil levar a cabo atividades relacionadas com essa competência.

No que se refere ao reconhecimento, construção e representação espacial do corpo a nível homolateral, podemos analisar os seguintes dados: 
- Inquiridos, na questão 15, sobre se a musicoterapia em geral, quando aplicada a pessoas com paralisia cerebral melhora a capacidade de reconhecimento, construção e representação homolateral do corpo, cerca de $85 \%$ dos professores entrevistados afirmam que sim. A percentagem que falta para os $100 \%$, simplesmente, não respondeu à questão.

- Questionados, na questão 22, sobre se o método de musicoterapia de John Bean, quando aplicado a pessoas com paralisia cerebral melhora a capacidade de reconhecimento, construção e representação homolateral do corpo, cerca de $57 \%$ dos professores entrevistados afirmam que sim. A percentagem que falta para os $100 \%$ não emitiu qualquer opinião.

- Cem por cento dos alunos entrevistados referem, na questão 13, sentir mais facilidade no reconhecimento, construção e representação do corpo a nível homolateral.

Sobre o reconhecimento, construção e representação espacial do corpo a nível heterolateral, verifica-se que:

- Cerca de setenta e um por cento dos professores entrevistados referem, na questão 16, que a musicoterapia em geral, quando aplicada a pessoas com paralisia cerebral, melhora a capacidade de reconhecimento, construção e representação heterolateral do corpo. A percentagem que falta para os 100\%, simplesmente, não respondeu à questão.

- Aproximadamente 57\% dos professores entrevistados referem, na questão 23, que o método de musicoterapia de John Bean, quando aplicado a pessoas com paralisia cerebral, melhora a capacidade de reconhecimento, construção e representação heterolateral do corpo. A percentagem que falta para $100 \%$, simplesmente, não respondeu à questão.

- A unanimidade mantém-se, uma vez que 100\% dos alunos entrevistados referem, na questão 14, sentir mais facilidade na representação espacial do corpo (reconhecimento, construção e representação do corpo a nível heterolateral).

Sobre a representação espacial do corpo (reconhecimento, construção e representação espacial do corpo a nível homo e heterolateral) é possível analisar que:

- Colocada a questão 11, se consideram que a musicoterapia quando aplicada a pessoas com paralisia cerebral melhora a representação espacial do corpo das mesmas e em que aspectos (pergunta 11), cerca de $85 \%$ dos professores entrevistados referem que sim e especificam que melhora a: consciência do próprio corpo; a percepção do espaço que os rodeia e a sua representação espacial.

- Cerca de $71 \%$ dos professores entrevistados referem, na questão 17, que a musicoterapia, quando aplicada a pessoas com paralisia cerebral, melhora a representação espacial do corpo das mesmas.

- Colocada a questão 18: Considera que o método de musicoterapia de John Bean quando aplicado à paralisia cerebral melhora a representação espacial do corpo? 
Se sim, em que aspectos? Cerca de 57\% dos professores entrevistados referem que sim, a restante percentagem não se pronunciou.

- Inquiridos, na questão 24, sobre se o método de musicoterapia de John Bean melhora a capacidade de reconhecimento, construção e representação homo e hetrolateral do corpo, de pessoas com paralisia cerebral, cerca de $57 \%$ dos professores entrevistados afirmam que sim.

Nos últimos quatro pontos, a percentagem que falta para os $100 \%$, simplesmente, não respondeu à questão.

- Abordada a questão cinco, sobre os contributos da musicoterapia quando aplicada à paralisia cerebral, cerca de $71 \%$ dos professores entrevistados referem, ("Não só trabalhamos a linha média ao tocar um tambor... A noção de dentro e fora do corpo, esquema corporal e consciência do próprio corpo...").

- Cem por cento dos alunos entrevistados referem, nas questões oito, nove e 15, ter sentido melhoras após as sessões de musicoterapia, e mais facilidade na representação espacial do corpo (reconhecimento, construção e representação do corpo a nível homolateral e heterolateral).

Sobre outros contributos do método de musicoterapia de John Bean e da musicoterapia em geral, constatou-se que:

- Na questão três, todos os professores entrevistados referem variados objetivos que têm enquanto musicoterapeutas. Objetivos estes que vão para além da representação espacial do corpo, nomeadamente objetivos relacionados com a linguagem; lateralidade; discriminação e memória auditiva; motricidade; orientação espaçotemporal; comunicação de emoções; desenvolvimento de competências pessoais e de grupo, relacionais e cognitivas.

Melhoria da qualidade de vida; estimulação da curiosidade sensorial; alargamento das capacidades psicomotoras ; desenvolvimento da capacidade de comunicação não verbal, da autoestima e da autoconfiança; desenvolvimento da capacidade de observação e de respeito pelas regras definidas; afirmação e reforço da personalidade; promoção e desenvolvimento da expressão, entre outros.

- Questionados pelos motivos que justificam a utilização da musicoterapia na reabilitação de pessoas com paralisia cerebral, cerca de $85 \%$ dos professores entrevistados referem, na questão quatro, entre outras coisas, a coordenação motora, o controle corporal e o controle da cabeça, braços e pernas.

- A percentagem que falta para os $100 \%$ não respondeu à questão.

- Abordada a questão cinco, sobre os contributos da musicoterapia quando aplicada à paralisia cerebral, 100\% dos professores entrevistados referem, [...] “Não só trabalhamos a linha média ao tocar um tambor... A noção de dentro e fora do corpo, esquema corporal e consciência do próprio corpo [...]"; “[...] ajuda na motricidade e na organização espaçotemporal [...]" e "[...] melhorar...atitude perante o seu próprio corpo [...]". 
- Na questão oito, os alunos perante a questão “Depois das sessões de musicoterapia, sentiste algumas melhoras?", os mesmos são unânimes em referir que sim.

\section{Conclusões}

Qual a influência do método de musicoterapia de John Bean e da musicoterapia no geral, na representação espacial do corpo (reconhecimento, construção e representação homo e heterolateral), de pessoas com paralisia cerebral? Perante esta questão, como conclusão final dos resultados obtidos, quer do teste experimental de representação espacial do corpo, quer das entrevistas a alunos e a professores de musicoterapia, poderemos afirmar que sim e que essa influência é positiva.

- Pois os resultados obtidos no teste experimental de representação espacial do corpo, pelo grupo experimental foram sempre superiores, após este grupo ter beneficiado das sessões de musicoterapia, exceto na parte do reconhecimento.

- Poderíamos colocar aqui em causa a parte do reconhecimento, contudo, o grupo experimental obteve melhores resultados que o grupo de controle, nesta mesma parte.

- Ainda no mesmo teste, o grupo experimental obteve sempre melhores resultados que o grupo de controle, em todas as parte e provas do teste, exceto na parte homolateral.

- Poderíamos colocar também em causa a prova homolateral, contudo o grupo experimental, após as sessões de musicoterapia apresentou, nesta prova, melhores resultados que antes de beneficiar das mesmas.

- Apesar de existir alguma percentagem de professores entrevistados, que simplesmente não respondeu às questões, oscilando essa percentagem entre os 16 e os $44 \%$, todas as respostas dadas vão no sentido de o método de musicoterapia de John Bean e a musicoterapia no geral desenvolverem capacidades relacionadas com a representação espacial do corpo (reconhecimento, construção e representação homo e heterolateral) de pessoas com paralisia cerebral.

- A unanimidade, sempre presente nas respostas dos alunos entrevistados, não deixa dúvidas que os mesmos consideram que o método de musicoterapia de John Bean desenvolve capacidades relacionadas com a representação espacial do corpo (reconhecimento, construção e representação homo e heterolateral), de pessoas com paralisia cerebral.

Além desta conclusão, poderemos depreender uma outra, esta de âmbito mais geral; além da musicoterapia influenciar positivamente a representação espacial do corpo de pessoas com paralisia cerebral, também lhe são reconhecidos outros contributos, pois: 
- Segundo todos os professores, são reconhecidos contributos, nomeadamente na área da: linguagem; lateralidade; discriminação e memória auditiva; motricidade; orientação espaçotemporal; comunicação de emoções; desenvolvimento de competências pessoais e de grupo, relacionais e cognitivas; melhoria da qualidade de vida; estimulação da curiosidade sensorial; alargamento das capacidades psicomotoras; desenvolvimento da capacidade de comunicação não verbal, da autoestima e da autoconfiança; desenvolvimento da capacidade de observação e de respeito pelas regras definidas; afirmação e reforço da personalidade; promoção e desenvolvimento da expressão, entre outros.

As afirmações de todos os alunos, se bem que genéricas, vão ao encontro desta conclusão ao referirem que sentiram melhoras, após as sessões de musicoterapia.

\section{IMPLICAÇÕES}

A conclusão final e a conclusão de âmbito mais geral deste estudo têm como implicação reconhecer que a musicoterapia pode assumir grande importância na ida ao encontro das necessidades sentidas por pessoas com paralisia cerebral.

Poder-se-á olhar para a musicoterapia como uma terapia estimulante e agradável e que adquire no âmbito socioeducativo extrema importância por pretender desenvolver um meio musicoterapêutico a ser utilizado no tratamento/ intervenção da representação espacial do corpo de pessoas com paralisia cerebral.

A sua utilização poderá implicar o melhoramento da qualidade de vida, não só destas pessoas, mas também dos pais, terapeutas, professores e outros que com elas sofrem as consequências de um comprometimento motor e de outras problemáticas que por vezes se encontram associadas a paralisa cerebral.

\section{REFERÊNCIAS}

AJURIAGUERRA, J. ; STUCKI, J. D. Developmental disorders of the body schem. North Holland: Publishing Co., 1972.

GONZÁLEZ, J. N. Alteraciones del habla en la infancia. Madrid: Panamericana, 2003.

HERCEBERG, P. La Parálisis Cerebral. Minusval, v151, p.13-15, 2005.

PRIETO, A. Niños y niñas con parálisis cerebral. Madrid: Narcea S.A, 1999.

RODRIGUES, D. A representação espacial do corpo em crianças com paralisia cerebral. Lisboa: Instituto Nacional de Investigação Científica, 1998.

TORO, M. Fundamentos de musicoterapia. Madrid: Morata. 2000.

WIGRAM, T. The art and science of music therapy. Singapore: Harwood Academic Publishers, 1995.

Recebido em: 07/06/2010

Aprovado em: 04/11/2010 